\title{
Evaluation of efficacy of microwave oven irradiation in disinfection of patient derived dental cast
}

\author{
Vidya Bhat, Kamalakanth Shenoy, Shravan Shetty \\ Yenepoya University, Mangalore, INDIA
}

\begin{abstract}
The purpose of this study was to check the efficacy of household microwave oven irradiation in disinfection of dental gypsum casts obtained from patients. Impressions of upper arch of 10 volunteers were made using irreversible hydrocolloid. The casts were poured in type III gypsum. All casts were cut into two halves. One half of each cast was irradiated in a microwave oven, set at $650 \mathrm{~W}$ for a total of 3 minutes and the un-irradiated half was used as control. Suspension of casts was inoculated directly on Tryptone Soya Agar plates (TSA) by spread plate method. The inoculated plates were incubated aerobically at $32^{\circ} \mathrm{C}$ for 48 hours. Colonies grown on the agar plates were counted using a plate count reader. The data is presented as CFU/cast. It was concluded that three minutes microwave irradiation at $650 \mathrm{~W}$ is effective to reduce the microbial load of dental casts. Routine use of microwave for disinfection of cast could be recommended and used in between procedures to prevent cross contamination in the dental clinics.
\end{abstract}

\section{Key words}

Microwaves; bacteria, radiation effect; dental models, microbiology; disinfection, methods

\section{Corresponding Author}

Vidya Bhat

Yenepoya University, Mangalore, INDIA

Email: vidya.bhat@yenepoya.edu.in 


\section{Introduction}

In dentistry, gypsum casts potentially contaminated with microorganisms are transported between dental clinics and dental laboratory. Routinely disinfection procedures on impressions are not followed in clinical practice. $^{1}$

The responsibility of ensuring that all materials have been cleaned and disinfected before dispatch to dental laboratory lies solely with the dentist. Many studies have been performed to evaluate effects of various disinfectants on different types of impression materials. No single disinfectant is compatible with all impression materials. Disinfectant spray and immersion are used to disinfect irreversible hydrocolloid impression materials before pouring the casts or shipping to the laboratory. Most reports indicate dimensional stability is not significantly affected by immersion technique and immersion is more likely to assure exposure of all surfaces of the impression to the disinfectant for the recommended time; however hydrocolloids and polyether materials cannot be immersed in disinfectants due to potential for absorption and distortion. Immersion disinfectants can only be used once before discarding (except for glutaraldehydes). Spraying disinfectants onto the surface of the impression reduces the chance of distortion, especially in the case of alginate, hydrocolloid and polyether materials and uses less disinfectant, but may not adequately cover areas of undercuts and can be released into air increasing occupational exposure. ${ }^{2,3}$ Recently, antimicrobial agents have been incorporated into the composition of the impression materials during manufacture. But, incorporation of the antimicrobial appears to increase the risk for dermal and mucosal irritation when multiple impressions are made. ${ }^{4}$

Chemical disinfectants used for disinfection of impressions have a number of problems associated with their use, that is they are time consuming and expensive to perform in dental practice. Another disadvantage with chemical method of disinfection is that some of the chemical disinfectants need to be freshly prepared or have a limited shelf life. Potential bacterial contamination has been detected even after disinfection had been performed. ${ }^{5}$ Even a cast from a properly disinfected impression may subsequently become contaminated by clinician, technician or by patient during subsequent dental procedures.
Some methods have been tried for disinfection of casts which includes incorporation of disinfectants into dental casts ${ }^{6}$ and disinfection of casts using microwave ovens in controlled settings. ${ }^{7}$ However, there is limited information on disinfection of casts using microwave ovens under clinical conditions. Since conventional autoclaving of the dental cast could easily damage the surface of the dental stone and immersion of the cast in chemical disinfectant could lead to dissolution of sufficient amount of gypsum to cause measurable reduction in dimensions of the cast and decrease in the compressive strength of the dental stone, microwave oven disinfection might provide a convenient solution. The potential for cross-contamination with dental casts is especially prevalent in prosthodontics because of multiple opportunities for the transfer of infectious agents from saliva to dental casts. Therefore disinfection of these cast should be done after each clinical and laboratory procedures.

A study conducted on high level microwave disinfection of dental gypsum cast revealed that there was a striking reduction of bacteria on the casts after 5 minutes of microwave oven irradiation in an ordinary household microwave oven set at 900 wattage. $^{7} \mathrm{~A}$ study conducted to determine if gypsum casts were potential source of microbial cross-contamination concluded that high potential exists for contamination of gypsum casts that were secured from impression and gypsum casts were source of cross-contamination between patients and dental personnel. ${ }^{8}$ It has been shown that microwave disinfection is an effective, quick, easy, and inexpensive versatile tool that can be performed by dentists, assistants, technicians, patients and/or their caregivers to inactivate microorganisms. ${ }^{9}$ The present study was undertaken to know the efficacy of household microwave oven in the disinfection of dental cast.

\section{Methods}

Ethical committee clearance from the Yenepoya university ethics committee and informed consent from the volunteers were taken before starting the procedure. Impressions of upper arch of ten volunteers from both sexes were made with an irreversible hydrocolloid in the department of prosthodontics, Yenepoya dental college. The casts were poured in type III gypsum. All casts were cut transversely with 
a plaster knife before the gypsum had fully set to facilitate subsequent division. The casts were removed from impressions approximately 45 minutes after pouring and broken into two equal parts. The casts were immediately transported in a sterile plastic bag to the research laboratory for further studies.

\section{Microwave irradiation}

One half of each cast was irradiated in a microwave oven, set at $650 \mathrm{~W}$ and $2450 \mathrm{MHz}$ frequency, for a total of 3 minutes and the un-irradiated half was used as control.

\section{Bacteriological studies}

Viable counts of bacteria were obtained by standard plate count method. Both test and control casts were transferred to $100 \mathrm{ml}$ of sterile MilliQ water in separate sterile $1 \mathrm{~L}$ beakers. The beakers with casts were kept under shaking for 20 minutes. From each test and control beakers, $100 \mu \mathrm{L}$ of the suspension was inoculated directly on Tryptone Soya Agar plates (TSA) by spread plate method. The inoculated plates were incubated aerobically at $32^{\circ} \mathrm{C}$ for 48 hours. Colonies grown on the agar plates were counted using a plate count reader [Digital Colony Counter]. The data is presented as CFU/cast.

\section{Results}

The total counts of bacteria varied between 1.24 $x 10^{5} \mathrm{CFU}$ to $5.38 \times 10^{5} \mathrm{CFU}$ in the control group.
But after microwave irradiation significant decrease was observed (Table I). Hundred percent decrease was observed in 30\% samples and on average 99\% decrease was evident.

\section{Discussion}

From this study effective reduction of bacteria on the dental cast was found after 3 minutes of microwave irradiation in a microwave oven set at $650 \mathrm{~W}$. Disinfection here can be performed quickly, repeatedly without the use of chemicals. Significant decrease in total counts of bacteria was observed after microwave irradiation.

A study conducted on high level microwave disinfection of dental gypsum cast revealed striking reduction of bacteria but however stated that relatively few bacteria would be transferred to the impression material from bacterially contaminated metal models, with their thinly distributed bacterial layer which hardly simulates the clinical situation. Routinely in clinical practice dental plaque containing bacteria in great concentration, is likely to adhere to and become embedded in the impression material. ${ }^{7}$ The present study has been done on patient derived dental cast so that exact clinical situations are utilized.

The fabrication of prostheses for infectious disease carriers presents a cross contamination hazard. Casts, dentures, crowns, bridges, impressions and

Table I. Percentage reduction of viable counts on casts

\begin{tabular}{rrrr} 
& \multicolumn{2}{c}{ Viable Counts (CFU/cast) } & Percentage Reduction (\%) \\
\cline { 2 - 4 } Sample No. & Control & Test & 98 \\
\hline 1 & $4.60 \times 10^{5}$ & $10 \times 10^{3}$ & 100 \\
2 & $4.12 \times 10^{5}$ & 0 & 100 \\
3 & $4.46 \times 10^{5}$ & 0 & 97 \\
4 & $1.24 \times 10^{5}$ & $4 \times 10^{3}$ & 100 \\
5 & $1.88 \times 10^{5}$ & 0 & 99 \\
6 & $1.50 \times 10^{5}$ & $2 \times 10^{3}$ & 97 \\
7 & $2.04 \times 10^{5}$ & $6 \times 10^{3}$ & 98 \\
8 & $5.38 \times 10^{5}$ & $10 \times 10^{3}$ & 99 \\
9 & $4.32 \times 10^{5}$ & $6 \times 10^{3}$ & 98 \\
10 & $3.32 \times 10^{5}$ & $6 \times 10^{3}$ &
\end{tabular}


other saliva or blood coated items are all exposed to contamination in the patient's mouth. Such items can spread infectious agents to similar items within the laboratory, where technicians and other patients are vulnerable to exposure. In one such study it was demonstrated that microorganisms could be transferred and recovered from gypsum casts on separation from contaminated impressions, thereby confirming dental casts as a medium of cross contamination between patients and dental personnel. ${ }^{8}$

Microwave irradiation, as has been tested previously to determine its effect on strength and hardness of the cast, $^{10-12}$ the resulted in improvement in these qualities, but there was some concern that cracks or porosities in the surface might occur when type III gypsum were exposed to irradiation with a very high wattage $(1,450 \mathrm{~W}) .{ }^{11}$ However further studies are required to know more about the possible effects of microwave irradiation on physical properties of dental casts.

The clinical relevance of impressions and dental casts microwave disinfection is that this procedure can be performed quickly and repeatedly, without the use of toxic, pungent, or allergenic chemicals. However, the disinfection of impression materials hinders possible cross-contamination only at the time the cast is poured. Because casts can become contaminated after the intra-oral adjustments of dental appliances, they must be regarded as the major vehicle for crosscontamination and can be disinfected using microwave energy throughout all phases of the dental treatment. ${ }^{9}$

\section{Conclusion}

Three minutes microwave irradiation at $650 \mathrm{~W}$ is effective to reduce the microbial load of dental casts. Routine use of microwave for disinfection of cast could be recommended and used in between procedures to prevent cross contamination in the dental clinics.

\section{Acknowledgments}

Yenepoya research centre for all their valuable assistance in the project work.

\section{Reference}

1. Almortadi N, Chadwick RG. Disinfection of dental impressionscompliance to accepted standards. Br Dent J 2010; 209(12): 607-611. http://dx.doi.org/10.1038/sj.bdj.2010.1134

2. Anonymous. Infection control practices in the dental laboratory. http://wsci.us/documents/usaflabic.ppt [Accessed October 5, 2011].

3. Herrera SP, Merchant VA. Dimensional stability of dental impressions after immersion disinfection. / Am Dent Assoc 1986; 113(3): 419-422.

4. Baker PS, Plummer KD, Parr GR, et al. Dermal and mucosal reactions to an antimicrobial irreversible hydrocolloid impression material: a clinical report. J Prosthet Dent 2006; 95: 190-193. http://dx.doi.org/10.1016/j.prosdent.2006.01.008

5. Egusa $\mathrm{H}$, Watamoto T, Matsumoto T, et al. Clinical evaluation of the efficacy of removing microorganisms to disinfect patient-derived dental impressions. Int / Prosthodont 2008; 21(6): 531-538.

6. Mansfield SM, White JM. Antimicrobial effects from incorporation of disinfectants into gypsum casts. Int J Prosthodont 1991; 4(2): 180-185.

7. Berg E, Nielsen O, Skaug N. High level microwave disinfection of dental gypsum cast. Int J Prosthodont 2005; 18(6): 520-525.

8. Leung RA, Schonfeld SE. Gypsum casts as a potential source of microbial cross-contamination. J Prosthet Dent 1983; 49: 210-211. http://dx.doi.org/10.1016/0022-3913(83)90503-6

9. Carlos EV, Garcia GRD, Nordi NDL, et al. Microwave assisted disinfection method in dentistry. http://www.intechopen.com/ source/pdfs/17009/InTech-Microwave_assisted_disinfection_ method_in_dentistry.pdf [Accessed October 1, 2011].

10. Hersek N, Canay S, Akça K, et al. Tensile strength of type IV dental stones dried in a microwave oven. J Prosthet Dent 2002; 87(5): 499-502. http://dx.doi.org/10.1067/mpr.2002.124095

11. Luebke RJ, Chan KC. Effect of microwave oven drying on surface hardness of dental gypsum products. I Prosthet Dent 1985; 54(3): 431-435. http://dx.doi.org/10.1016/00223913(85)90566-9

12. Luebke RJ, Schneider RL. Microwave oven drying of artificial stone. J Prosthet Dent 1985; 53(2): 261-265. http://dx.doi. org/10.1016/0022-3913(85)90124-6 